\title{
Práticas e discursos académicos sobre biblioterapia Desenvolvidas em Portugal'
}

\section{Practices and Academic Discourses on Bibliotherapy in Portugal}

\author{
FERNANDO FRAGA AZEVEDO \\ KARLA HAYDÊ OLIVEIRA \\ Universidad do Minho \\ Portugal \\ fraga@ie.uminho.pt \\ karlahayde@yahoo.com.br
}

(Recibido: I8-I2-20I5; aceptado: 27-08-20I6)

Resumen. Este artigo define o conceito de biblioterapia e faz o mapeamento da produção académica sobre a temática existente em Portugal. Para o efeito, foram analisadas as práticas e a produção de trabalhos académicos desenvolvidos nos cursos de pós-graduação presentes na base de dados do Repositório Científico de Acesso Aberto de Portugal (RCAAP). Considera-se que a técnica da biblioterapia é eficaz em diferentes contextos e aplicabilidades, sejam estes crianças, adultos ou idosos.

Palavras-Chave: biblioterapia; leitura; livros.
Abstract.This paper defines the concept of bibliotherapy and maps the existing academical literature on the subject in Portugal. For this purpose, the practices and the production of academical works in portuguese postgraduate courses presented in the Scientific Repository Database of Open Access (RCAAP) were analyzed. Bibliotherapy is considered a technique that is effective in different contexts and applicability, whether children, adults or the elderly.

Keywords: bibliotherapy; reading; books.

\footnotetext{
${ }^{\text {I }}$ Para citar este artículo: Fraga Azevedo, Fernando y Haydê Oliveira, Karla (20I6). Práticas e discursos académicos sobre biblioterapia desenvolvidas em Portugal. Alabe 14. [www.revistaalabe.com]

DOI: Io.I5645/Alabe20i6.I4.6
} 


\section{Introdução}

Desde a primeira definição cunhada em I94I pelo dicionário especializado norteamericano Dorland's Ilustrated Medical Dictionary, definindo-o como "o emprego de livros e a leitura deles no tratamento de doença nervosa", que o termo biblioterapia vem tomando novas projeções. Como bem referencia o dicionário, em princípio era utilizada como uma ação em caráter corretivo, em casas de saúde, para a cura e tratamento de indivíduos com distúrbios emocionais. No entanto, esta visão se modificou, e hoje esta atividade vislumbrou um novo olhar. A biblioterapia (re) surge trazendo uma mudança na concepção dos aplicadores, assumindo também, um caráter preventivo para possibilitar o desenvolvimento pessoal em diferentes faixas etárias (crianças, adultos e idosos), geralmente aplicada em escolas, bibliotecas, hospitais, presídios, orfanatos, e etc.

A biblioterapia não é uma atividade nova, esta remonta aos nossos antepassados. Aristóteles (I986) enaltece a representação artística da tragédia clássica grega capaz de transformar o terror e a piedade em uma alegria estética, produzindo, dessa forma, a purificação da alma ao atingir a catarse. Assim, a função catártica pode ser compreendida como a expurgação dos sentimentos e das emoções que atormentam a alma por meio da representação artística, ademais "il soit possible de remplacer la scène théâtrale par la scène littèraine" (Ouaknin, r994: I9).

De acordo com a etimologia da palavra biblioterapia significa terapia por meio de livros. Assim, admite-se que há alívio, cura e tratamento por meio da palavra escrita dos textos literários. Neste sentido, este artigo tem como finalidade sistematizar a produção acadêmica e ações sobre biblioterapia desenvolvidas em Portugal, o que torna particularmente significativo, pois permite vislumbrar os reflexos das pesquisas científicas no país potencializando o diálogo com a comunidade nacional e internacional.

\section{De que falamos quando falamos de Biblioterapia?}

Discorrer sobre a história de algum tema com precisão pode-se tornar um assunto complexo e errante. Grandes controvérsias são mantidas, embora a literatura afirme que a biblioterapia é uma atividade desenvolvida há bastantes tempos remotos. Há, no entanto, um consenso entre vários autores que, desde os tempos antigos, a bíblia já era utilizada como "remédio" para os males da alma, permanecendo sua vitalidade até os dias atuais.

No século XIX, o pioneiro deste método foi o norte americano Benjamim Rush que passou a recomendar a leitura como apoio à psicoterapia para o tratamento de doentes mentais portadores de conflitos internos, desânimo, medos, e no avanço da condição de vida dos idosos (Alves, I982). 
Em tempos mais recentes, a partir da Primeira Guerra Mundial, os psiquiatras notaram que os pacientes, que tinham acesso aos textos literários, apresentavam uma recuperação mais acelerada em relação àqueles que não utilizavam o recurso da leitura. Deste modo, a American Library Association (ALA) reconheceu a leitura literária como terapia e recomendou programas de apoio aos hospitais para o processo de reabilitação e entretenimento dos soldados ao retornar da guerra sendo vítima de estresse pós-traumático. Assim, surgiam as bibliotecas dos hospitais nos primeiros anos do séc. XX.

A utilização da prática antecede a nomenclatura "biblioterapia”. Esta surgiu somente no século XX, em ı9ı6, na América do Norte pelo americano Samuel McChord Crothers, para denominar essa nova ciência. Em I9O4, a biblioterapia passa a ser considerada um ramo da biblioteconomia. É consolidada como um campo de pesquisa em I93o. Assim, a partir desta data, novos trabalhos e pesquisas surgem para o crescimento deste estudo, e com a evolução desta técnica, a biblioterapia assume diferentes segmentos, passando a admitir outra forma de terapia, de caráter preventivo, para o entretenimento, o desenvolvimento pessoal e a formação de leitores em diferentes abordagens, públicos e contextos.

Caroline Shrodes (1949) foi a primeira pesquisadora norte - americana a reformular o conceito de biblioterapia como um "processo de interação dinâmica entre a personalidade do leitor e a literatura que pode atrair as emoções do leitor e liberá-las para o uso consciente e produtivo". Pela definição referenciada podemos observar que se aproxima muito da realidade atual, e foi a partir dessa autora que a biblioterapia ganhou maiores projeções.

Porém, em I96I, o dicionário não especializado Webster's Third International Dictionary o definiu como o "uso de material de leitura selecionado, como ferramenta terapêutico em medicina e psiquiatria" e, também, "guia na solução de problemas pessoais através da leitura dirigida”. São acepções tautológicas, em que confirma a primeira definição do dicionário Dorland's Ilustrated Medical Dictionary, legitimando o fosso existencial entre a palavra e o significado e os escassos conhecimentos linguísticos não sendo capazes de suportar a evolução da biblioterapia já apresentada por Caroline Shrodes em I949.

Segundo o francês Marc-Alain Ouaknin (1996), são definições restritas e preconceituosas em relação à medicina e o significado do termo "terapia". Este autor recorreu seus estudos baseados na linguística e nos estudos culturais de diferentes países para explicar o significado da palavra biblioterapia fazendo uma advertência com relação à etimologia. Para este autor, biblioterapia significa terapia por meio de livros. Em inglês e em francês, a palavra “terapia” tem essencialmente um caráter curativo. Já no grego e no hebraico, tem um caráter preventivo. O terapeuta significa aquele que cuida desse sopro que dá forma ao corpo, seu papel será o de desatar os nós da alma (Ouaknin, r994). Enquanto a medicina preocupa-se com a saúde do corpo, a terapia transcende os cuidados com o corpo buscando atingir a essência do ser. 
Saindo em defesa de um conceito mais amplo, as pesquisadoras portuguesas Ana Cristina Abreu e Anabela Henriques, em acordo com a pesquisadora espanhola Maria Ángeles Zulueta (20I3: 96), corroboram com a área, propondo a seguinte definição:

A biblioterapia é uma atividade com vertentes preventiva e terapêutica que, através da leitura de livros de ficção ou de auto-ajuda, individualmente ou em grupo, tem o propósito de facultar uma experiência recobradora da saúde, ou permitir um contínuo desenvolvimento, em qualquer idade do ciclo vital.

Nesta perspectiva, podemos inferir que a biblioterapia é a leitura de palavras benditas que alimentam o espírito e fortalecem o corpo, proporcionando um bem-estar humano. Assim, podemos observar na literatura que o conceito de biblioterapia na visão de diferentes autores possui um significado distinto. Porém, estes não se contrapõem ao afirmar que a leitura pode ser uma terapia.

Neste sentido, para a aplicação desta técnica, o método biblioterapêutico consiste no planeamento da ação e na magia da arte interpretativa do texto, em que a criatividade, a interação e o diálogo entre os participantes durante e após a leitura é uma condição sublime nesse processo. Fazendo uma analogia ao teatro, a biblioterapia apresenta vários elementos de uma grande peça teatral em que se apresentam em um lugar predeterminado, com um roteiro planejado nos bastidores, podendo possuir elementos como: figurinos, maquiagens, cenografia, sonoplastia, etc. Sendo que o livro é o grande protagonista, o biblioterapeuta é o coadjuvante ou o personagem secundário, o público é o espectador, e posteriormente o antagonista, em oposição a um conflito.

Neste cenário, todos são atores e fazem parte de um mesmo processo criativo e interativo em busca do bem-estar e equilíbrio do corpo e do espírito. Além da importância do livro, outros componentes são inerentes, pois “a bilioterapia contempla não apenas a leitura, mas também o comentário que lhe é adicional" (Caldin, 200I:36). De tal modo, que a leitura por si só, não se designa em biblioterapia. Para compor seu efeito terapêutico é necessário o acompanhamento de um biblioterapeuta que, por meio do diálogo, haja reflexão, após a leitura do texto.

Neste contexto, as palavras ganham significados num debate interativo entre os elementos - livro, biblioterapeuta e leitores/ouvintes - conduzindo o leitor/ouvinte a uma tempestade de ideias, os chamados brainstorming, que levam o participante a sair de um estado de letargia em que se encontrava ao encontro de um mundo de possibilidades. 


\section{Discursos Académicos e Práticas sobre Biblioterapia em Portugal}

No sentido de reunir os estudos consoante o item referido, neste artigo procuraremos estruturar os discursos acadêmicos e práticas desenvolvidas em Portugal para elucidar a evolução da biblioterapia portuguesa. Utilizaremos como fonte de coleta de dados o Repositório Científico de Acesso Aberto de Portugal - RCAAP (www.rcaap.pt). Essa base de dados disponibiliza on-line as informações referentes às teses de mestrado e doutoramento nas diversas áreas do conhecimento defendidas junto aos cursos de pósgraduação. A busca da pesquisa foi realizada a partir da palavra - chave Biblioterapia. Foram incluídos todos os trabalhos académicos que versaram sobre o tema, dez dissertações e quatro artigos. Com relação às práticas, localizamos duas desenvolvidas no país. Estas foram buscadas nos jornais do país e nas páginas da web. A lista apresentada está organizada por ordem cronológica de publicação dos trabalhos.

Ana Paula Monteiro (2004), licenciada em enfermagem de saúde mental e psiquiátrica, mestre em sociologia e professora adjunta da Escola Superior de Enfermagem de Bissaya Barreto - Coimbra publicou um artigo "Biblioterapia como intervenção de enfermagem de saúde mental e psiquiátrica”, em 2004. Com esta comunicação abordou o conceito de biblioterapia como técnica de intervenção dirigida a utentes de saúde mental. Enfatizou o benefício do uso da literatura (ficção ou poema) em contexto terapêutico na recuperação e tratamento de utentes. Relata que a biblioterapia é uma atividade interdisciplinar, podendo ser trabalhada com bibliotecários, escritores, pedagogos, psicólogos, médicos e terapeutas ocupacionais. Considerou que o enfermeiro que exerce a sua atividade em unidade de psiquiatria ou saúde mental pode incluir esta técnica em suas práticas de cuidados diferenciados a utente com patologia psiquiátrica.

Maria do Céu Gomes Nogueira Pontes (2008) desenvolveu o artigo "Da infância para o mundo: as leituras que educam para os valores e formam o carácter”, localizado no Repositório Científico do Instituto Politécnico do Porto - RECIPP, em que refletiu sobre a importância da leitura de contos de fadas para o desenvolvimento moral e ético na infância. Sugeriu exemplos de contos da literatura infantil que podem servir de âncora à formação do caráter. Aludiu sobre a importância do ritual da história à hora de dormir e da "hora do conto", focando o papel terapêutico de alguns contos através das linguagens simbólicas e dos afetos. Defendeu a leitura na aquisição de referências sólidas no âmbito de uma "ética de salvaguarda": de si, dos outros, da natureza e do mundo. Conclui indicando alguns projetos e no âmbito da educação e da formação ética para os valores que visam o crescimento mais responsável e mais feliz das crianças.

Rosa Maria Bandeira Paixão Mendes (2008) identificou, com sua dissertação de Mestrado em Educação e Bibliotecas, na Universidade Portucalense - Porto, de título "A literatura e a biblioterapia para crianças com problemas de aprendizagem”, as contribuições da aplicação da biblioterapia nas crianças com currículo alternativo. Trabalhou com livros da literatura infanto-juvenil aliados a atividades lúdicas, proporcionando momentos de lazer e diversão, favorecendo a catarse, a identificação e a introspecção por 
meio de textos literários que contemplassem o humor, facilitassem a socialização, estimulassem a criatividade e o diálogo, promovessem a leitura, incentivassem a interpretação, aliviassem as tensões diárias e aumentassem a autoestima dos alunos. Constatou que as leituras das histórias aliadas às atividades lúdicas complementares fortaleceram o grupo e demonstraram que a biblioterapia é eficaz como pacificação de emoções.

Marisa Pedrosa Tavares da Silva (2OII), com sua pesquisa para obter o grau de Mestre em Educação, na especialidade em Animação da Leitura, na Escola Superior de Educação de Paula Frassinetti - Porto, intitulada "Biblioterapia na educação pré-escolar: a gestão do medo e da agressividade", pretendeu com este projeto de investigação-ação promover a biblioterapia de desenvolvimento na educação pré-escolar fomentando a dimensão edificante das emoções, nomeadamente na gestão de duas emoções: o medo e a agressividade. Constatou que a fantasia e o mundo literário da literatura infantil contribuem na consciencialização das próprias emoções, extensível a valorização da autoestima, na importância e na necessidade da partilha e numa melhoria sensível na gestão das emoções.

Cristina Maria Rodrigues dos Santos Maltez (2OII), na sua dissertação em Gestão da Informação e Bibliotecas Escolares, pela Universidade Aberta, em Lisboa, com o trabalho "A biblioteca escolar e a biblioterapia: relato de uma experiência", considerou a importância da aplicação da biblioterapia a ser realizada pelo bibliotecário na biblioteca escolar. Realçou o valor psicológico da literatura infanto-juvenil, ou seja, a sua capacidade de refletir sobre as questões da vida, da realidade e de nos conduzir numa autoaprendizagem. Refletiu sobre o papel do livro e da leitura no âmbito da formação e do desenvolvimento emocional, psicológico, social e afetivo dos alunos, em especial no que se refere ao tema da morte. Propôs estratégias de atividades a realizar, neste contexto, pela biblioteca escolar, tendo como base os resultados levantados a um conjunto de alunos inquiridos através do questionário. Conclui sua pesquisa afirmando que, ainda, há um longo caminho a percorrer, nomeadamente: a existência de uma política de desenvolvimento da coleção na biblioteca escolar, formação do bibliotecário para esta prática e da criação de condições para a implementação da biblioterapia nas escolas que passa pela introdução da disciplina em cursos de biblioteconomia, ensino pré-escolar e primeiro ciclo.

Maria Madalena Barbosa Gomes Lopes Cristo Van-Zeller (20II) desenvolveu sua dissertação em Educação e Bibliotecas, pela Universidade Portucalense - Porto, intitulada "A biblioterapia como pedagogia atuante da leitura: um projeto de intervenção em contexto educativo". Lamentou o fato de o hábito da leitura ser reduzidos entre os adolescentes. Planejou as sessões biblioterapêuticas juntamente com os alunos participantes (sete alunos do $8^{\circ}$ ano). Trabalhou com poemas e livros da literatura infanto-juvenil. Verificou em que aspetos a biblioterapia pode contribuir para melhorar as relações interpessoais e o desempenho escolar em contextos sociais menos favorecidos. Constatou que a biblioterapia promoveu o desenvolvimento do pensamento crítico que conduz o autoconhecimento, a elevação da autoestima e das relações interpessoais. 
Maria Odete Rodrigues Gonçalves Ferreira de Almeida (2OI2), com a dissertação de mestrado em Ciências da Educação, pela Universidade Lusófona de Humanidades e Tecnologia - Lisboa, intitulada "A utilização da biblioterapia em contexto da biblioteca escolar no apoio a crianças com perturbações físicas e emocionais: criação de um modelo aplicacional”, considerou a importância e a necessidade de proporcionar aos alunos ambientes favoráveis de leitura, objetivando a autonomia e o diálogo interpretativo. Abordou sobre a pertinência da seleção de recursos literários para o sucesso das sessões de biblioterapia e relatou o potencial da literatura infantil nesta técnica. Recomendou a implantação de um programa de intervenção biblioterapêutica, em contexto de ambiente informal de aprendizagem na Biblioteca Escolar. Propôs desenvolver em trabalhos futuros, no âmbito da tese de doutoramento, uma investigação de cariz experimental que incida sobre a aplicação de um programa de intervenção de Biblioterapia e de Webterapia, em contexto de Biblioteca Escolar, junto de crianças portadoras de perturbações físicas e emocionais.

Maria Margarida Coelho Pereira Sebastião (2OI2), na sua dissertação intitulada "Biblioterapia: a função terapêutica do livro em ambiente prisional", para a obtenção do grau de Mestre em Ciências Documentais, pela Universidade Lusófona de Humanidades e Tecnologia - Lisboa, realizou um estudo empírico sobre a leitura terapêutica em contexto prisional. Para alcançar este objetivo formulou a seguinte hipótese: O livro exerce sobre as pessoas em geral e, de uma forma mais particular, sobre indivíduos em contexto de detenção institucional uma função terapéutica. Descreve as dinâmicas de biblioterapia realizadas nas prisões em Portugal. Relata sobre a importância do poema neste estabelecimento e que o acervo da biblioteca deverá incluir no seu acervo materiais impressos revistas, jornais, livros de ficção - e em outros formatos para abarcar as necessidades educativas, informativas e recreativas, na reabilitação dos presidiários e reinserção social. Concluiu que a prática de leitura de temas específicos em qualquer campo de atuação e sob orientação de um profissional com conhecimentos aprofundados tanto em relação às personalidades e problemas dos destinatários como aos materiais que tem à sua disposição - o livro, em sentido lato - pode efetivamente desencadear benefícios terapêuticos nos leitores.

Ana Cristina Abreu, Maria Ángeles Zulueta e Anabela Henriques (2013) publicaram o artigo "Biblioterapia: estado da questão" na Revista Cadernos BAD, da Associação Portuguesa de Bibliotecários, arquivistas e documentalistas. Mostraram, a partir de uma revisão da literatura, um panorama conceptual da biblioterapia para um melhor conhecimento da área, para compreender as suas raízes e perspectivar o seu devir. Problematizaram questões relativas à leitura e ao método como chave do sucesso biblioterapêutico, aos três tipos de biblioterapia clínica, institucional e desenvolvimento, bem como os seus benefícios. Relacionaram a biblioterapia no campo da biblioteconomia, na formação dos bibliotecários enquanto biblioterapeutas e quais os limites da sua intervenção. Referenciaram estudos com resultados bastante positivos na aplicação da técnica. 
No âmbito de sua dissertação de mestrado em Ciências Documentais pela Universidade Lusófona de Humanidades e Tecnologias - Lisboa, intitulada "Biblioterapia aplicada a idosos: Um novo desafio para as bibliotecas públicas portuguesas”, Carmem Zita Honório Santos Ferreira (2OI3) atestou, com a sua investigação, a importância da aplicação da Biblioterapia de desenvolvimento a indivíduos institucionalizados em centros de apoio e lares de idosos. Identificou as atividades de Biblioterapia que estão a serem promovidas atualmente pelas bibliotecas da Rede Nacional de Bibliotecas Públicas em Portugal, as metodologias utilizadas e os constrangimentos na aplicação das mesmas, no que se refere à população idosa. Referiu que as bibliotecas públicas utilizam em suas sessões livros de lendas tradicionais, contos, poesia, drama, jornais e revistas, romances e autoajuda. Constatou que os benefícios das leituras dirigidas, para fins de desenvolvimento pessoal com leitores idosos, em contexto de institucionalização, demonstram que se deve investir na aplicação da biblioterapia a idosos, em grande escala. Concluiu que as bibliotecas públicas e os bibliotecários têm um papel preponderante na aplicação desta terapia, através da interação com parceiros nas áreas da saúde, educação e ação social. Reafirmou a necessidade de se prosseguir este trabalho de forma sistematizada e regular a uma população específica: os idosos.

Graça Maria do Rosário Ribeiro Correia (2013) discutiu o papel da literatura na escola com fins terapêuticos. Em 2OI3, defendeu sua dissertação obtendo o título de mestre em Educação e Bibliotecas, na Universidade Portucalense - Porto, com o trabalho "A Morte na Literatura Infantojuvenil: da análise de obras literárias ao incentivo da Leitura desta problemática na 'Hora do Conto’ da Biblioteca Escolar”. Objetivou explorar a morte na literatura infanto-juvenil, em vinte obras com valor literário, de autores portugueses e estrangeiros, de clássicos a contemporâneos. Explorou as origens da literatura infanto-juvenil, bem como o papel dos professores bibliotecários e das bibliotecas escolares. Propôs sugestões a desenvolver na hora do conto pelas bibliotecas escolares e pelos professores bibliotecários nas escolas, tendo em vista a promoção da leitura desta temática emergente e a compreensão da mesma na vida diária.

Sirlene Cristófano (20I4), mestre em literatura, Culturais e Interartes, pela Faculdade de Letras Universidade do Porto - FLUP, por meio de conferências de Psicologia em Estarreja, divulgou o artigo "Biblioterapia e literatura infantojuvenil: educar para incluir, em vez de criminalizar para excluir” mostrou a utilização da literatura infantil enquanto promotora da formação da identidade de crianças marginalizadas, além de fazer uma reflexão sobre como a literatura infanto-juvenil desponta a possibilidade de educar para incluir, em vez de criminalizar para excluir. Defendeu ideia da biblioterapia como trampolim para a autoajuda, o autoconhecimento e o encontro com a autoestima. Verificou que na prática de biblioterapia há a preocupação em proporcionar ao público alvo textos que estimulam a alegria, o prazer, à descontração e elementos essenciais ao bem estar do leitor, além de cultivar os valores sociais como: respeito, justiça, solidariedade, compromisso, igualdade e democracia. Constatou que os contos maravilhosos são registos simbólicos, pelos quais a psique se manifesta, podendo assim contribuir para a formação harmoniosa do leitor, seja ele criança ou jovem. 
A autora da dissertação de mestrado em Ciências Documentais pela Universidade Lusófona de Humanidades e Tecnologia - Lisboa, cujo título se insere na "Biblioterapia aplicada em contexto de saúde mental: um estudo de caso”, Ana Mafalda Carvalho Silva (20I4) executou um trabalho a um grupo de pessoas adultas com necessidades psicossociais, com idades entre 2г e 49 anos, frequentadoras da Unidade Comunitária dos Cuidados Psiquiátricos de Odivelas - UCCPO. Verificou que os participantes tinham muita necessidade de falar dos seus problemas, e que quando o texto da sessão era mais reflexivo e acompanhado de música, os participantes contribuíam mais, o que significa que os textos reflexivos e a música podem ser uma boa ajuda para desencadear discussões acerca dos problemas pessoais dos utentes. Verificou também que se deve ter bastante cuidado na escolha dos textos para cada sessão de biblioterapia, e se deve sempre atender à sensibilidade dos participantes para o bom sucesso da sessão. Utilizou para as sessões: poemas, parábolas, contos portugueses, letras de canção. Os participantes também se projetaram nos textos lidos e comentários escritos, sendo possível saber um pouco mais de cada um deles através das suas contribuições baseadas nos textos e temas das atividades escritas. Avaliou a participação como positiva e que biblioterapia poderá ser aplicada futuramente no UCCPO. Constatou que essa técnica poderá ser bastante benéfica no tratamento e reabilitação dos utentes da mesma unidade.

Tiago Manuel Ribeiro Patrício (2OI4), com sua investigação para obter o título de mestre em Teoria da Literatura, na Universidade de Lisboa - Lisboa, com o trabalho "Recomendações de leitura e terapias literárias" contextualizou as aplicações da biblioterapia, comentou alguns efeitos conhecidos da leitura de alguns livros, e procurou entender de que forma se podem prescrever livros para determinados fins. Seu trabalho baseou-se em alguns autores, como Ezra Pound, no ensaio The serious artist, publicado em I9I3, defende que na literatura também existe a arte de diagnosticar e a arte de curar, tal como em medicina. A partir destas qualidades associadas à narrativa literária, duas terapeutas, Ella Berthoud e Susan Elderkin, mantiveram um consultório literário em Londres e editaram em 2013 uma espécie de prontuário literário, The Novel Cure: An A-Z of Literary Remedies, no qual aconselham romances para diversas doenças e para outros imprevistos. Estas autoras "prescrevem" romances literários porque consideram que apenas a forma narrativa oferece a possibilidade de desdobramento e da suspensão do tempo, uma vez que, segundo Marc-Alain Ouaknin, é através desses efeitos que se funda a possibilidade de regeneração e de abertura para outro tempo, numa temporalidade harmónica e equilibrada entre passado, presente e futuro. Paul Ricoeur também refere que o acesso ao tempo se dá através da narrativa, uma vez que o tempo é inapreensível e só se torna tempo humano na medida em que é articulado de um modo narrativo.

"A poesia não tem grades", trabalho pioneiro e voluntário desenvolvido por Felipe Lopes desde 2003, tem vindo a percorrer os estabelecimentos prisionais portugueses. Desenvolve sessões de promoção da leitura junto dos reclusos com o objetivo de promover a experimentação artística e assim contribuir para o desenvolvimento pessoal daquela população. Felipe Lopes é um dos fundadores do grupo "O contador de Histó- 
rias" e dedica-se à promoção do livro e da leitura há mais de 20 anos, incluindo escolas e bibliotecas. Recebeu, em 2OI2, o prêmio "Sorrir na Educação", pelo trabalho desenvolvido nesta área.

A Rede Nacional de Bibliotecas Públicas (RNBP) em Portugal, com o projeto "Biblioterapia para idosos", tem vindo a promover ao público sénior a terapia através do livro, da leitura e do conto, tentando, deste modo, minimizar a solidão, o isolamento social dos idosos e estimular as suas capacidades cognitivas, e encorajando-os a interagir, interpretar e comentar os textos apresentados. Em suas sessões utilizam livros de lendas tradicionais, contos, poesia, drama, jornais e revistas, romances e autoajuda.

\section{Considerações Finais}

Ao analisar a literatura académica e as práticas portuguesas, podemos inferir que a evolução do estado da arte e as práticas portuguesas encontram-se em situação privilegiada, pois seu acréscimo foi bastante expressivo na ultima década. Verifica-se que as maiores incidências desta atividade estão em ambientes escolares, de saúde, prisionais e lares de idosos, desempenhando a biblioterapia de desenvolvimento para efetivação desta técnica. Promovida por bibliotecário em consonância com professores, animador cultural, profissionais da área da saúde, esta se refere à prática que utiliza a literatura de ficção de forma imaginativa, como fonte de entretenimento e humor para a prevenção e alívio das tensões diárias a pessoas que não apresentam qualquer distúrbio ou comportamentos alterados. Sua proposta é utilizar os textos literários para as pessoas compreenderam melhor a si e o mundo, ao adquirir maturidade cognitiva para formular conceitos e solucionar questões quando o leitor se transporta a um universo paralelo ao encontro com as personagens da história.

Outro ponto a destacar, foi à busca pela qualidade dos textos literários para aplicação da técnica. No que se refere ao tipo de obras utilizadas nas sessões pelos trabalhos analisados sobressaem os poemas, as lendas portuguesas e os contos tradicionais da literatura infanto-juvenil. Os contos de fadas e as lendas resistiram ao tempo, porque, sendo fruto de saberes frequentemente considerados fundacionais ou primordiais no âmbito de uma comunidade, enfaticamente sublinham determinadas verdades axiológicas e/ ou simbólicas relevantes nesses contextos comunitários (Azevedo, 20I4). Com efeito, encontra-se em muitos contos e lendas a defesa de valores como a virtude, a resiliência, o trabalho e a esperteza. Assim, cada criança, jovem ou adulto, particularmente, procurará neste texto (ou no romance, ou no poema) um significado diferente de acordo com as suas necessidades e interesses em cada fase de sua vida em que nos falam de medos (Chapeuzinho Vermelho); de amor (A Pequena Sereia); da dificuldade de ser criança (Peter Pan); de carências (Joãozinho e Maria); de autoconhecimentos, autoaprendizagens, isolamento (O Patinho Feio); de coragem, lealdade e honestidade (As aventuras de Pinóquio); de perdas e buscas (O Gato das Botas); de morte (Romeu e Julieta; Pedro Alecrim); 
de rejeição (Cinderela); de insegurança ou de capacidade de agência (Alice no país das maravilhas; Mogli), de fé (A lenda da Santa Maria).

Portanto, o ato de ler e ouvir histórias, através do diálogo e da reflexão, aproxima povos, promove o respeito pela alteridade, possibilita interrogar o mundo. Os bons textos literários carregam consigo aquilo que realmente importa e interessa para o bemestar humano, tais como o amor a si mesmo e ao próximo, o interesse pela cultura, a sensibilidade ao belo, a conquista da liberdade, o respeito à vida, proporcionando um valor moral e terapêutico, para além de orientar a relação do ser humano com o mundo. Deste modo, todos os trabalhos elencados e analisados foram unânimes ao ressaltar as benesses da biblioterapia proporcionados a todos os envolvidos.

Desde o início de sua utilização até aos nossos dias, tem-se assistido uma crescente evolução entre a teoria e a prática. Essas mudanças também contribuem para o ressignificado de conceitos e da utilização. Longe de ser uma novidade, a biblioterapia caminha em todo lado e um pouco em todo mundo e (re) surge como uma ação inovadora acometida pela contemporaneidade. São formas diferentes de serviços que ou se transformam ou se modernizam, no diapasão da modernidade, ou estarão condenadas ao esquecimento, como tudo aquilo que se recusa a se transformar e a seguir o ritmo da história. 


\section{Referèncias}

- Abreu, A. C.; Zulueta, M. Á.; Henriques, A. (20I3). Biblioterapia: estado da questão. Revista Cadernos BAD,I/2, 95-IIo. Consultado em I4 de Novembro de 2OI5, http://www.bad. pt/publicacoes/index.php/cadernos

-Almeida, M. O. R. G. F. de (20I2). A utilização da biblioterapia em contexto de biblioteca escolar no apoio a crianças com perturbações físicas e emocionais: criação de um modelo aplicacional. Dissertação de mestrado, Universidade Lusófona de Humanidades e Tecnologias, Lisboa, Portugal. 2Iof. Consultado em I4 de Novembro de 20I5, http://recil.grupolusofona.pt/jspui/handle/IO437/3808

- Alves, M. H. H. (I982). A aplicação da Biblioterapia no processo de reintegração social. Revista Brasileira de Biblioteconomia e Documentação, I5, I/2, 54-6I.

-Aristóteles (1986). Poética. Lisboa: Imprensa Nacional Casa da Moeda.

-Azevedo, F. (20I4). Literatura Infantil e Leitores. Da Teoria às Práticas. Raleigh, N. C.: Lulu Press.

- Caldin, C. F. (200I). A leitura como função terapêutica: biblioterapia. Encontros Bibli. Revista de biblioteconomia e ciência da informação, Florianópolis, I2. Consultado em I4 de Abril de 20I4, https://periodicos.ufsc.br/index.php/eb/article/view/I5I82924.200Iv6ni2p32/5200

- Cordeiro, A. D. (20I5). Na prisão, aprendi que um livro faz parte de nós. Jornal Público, Portugal, 24-25, 03 de out.20I5.

- Correia, G. M. do R. R. (20I3). A Morte na Literatura Infanto-Juvenil: da análise de obras literárias ao incentivo da Leitura desta problemática na 'Hora do Conto' da Biblioteca Escolar. IO4 f. Dissertação de mestrado, Universidade Portucalense, Porto, Portugal. Consultado em I4 de Novembro de 20I5, http://repositorio.uportu.pt/jspui/handle/II328/787

- Cristófano, S. (20I4). Biblioterapia e literatura infantojuvenil: educar para incluir, em vez de criminalizar para excluir. III Congresso de Psicologia, Estarreja, Portugal. Consultado em I4 de Novembro de 20I5, http://www.cm-estarreja.pt/pdf/educacao/psicologia/3_congresso/Texto_Congresso\%2oEstarreja-I.pdf

- Ferreira, C. Z. H. S. (20I3). Biblioterapia aplicada a idosos: um novo desafio para as bibliotecas públicas portuguesas. Dissertação de mestrado, Universidade Lusófona de Humanidades e Tecnologias, Lisboa, Portugal. Consultado em I8 de Dezembro de 20I5, http:// recil.grupolusofona.pt/bitstream/handle/IO437/4940/FERREIRA_Carmen_Biblioterapia_Idosos_2OI3.pdf?sequence $=$ I 
- Maltez, C. M. R. dos S. (2OII). A biblioteca escolar e a biblioterapia: relato de uma experiência. Dissertação de mestrado em Gestão da informação e bibliotecas escolares. Dissertação de mestrado, Universidade Aberta, Lisboa, Portugal. I64 f. Consultado em 20 de Novembro de 20I5, http://repositorioaberto.uab.pt//handle/IO4OO.2/23O2

- Mendes, R. M. B. P. (2008). A literatura e a biblioterapia para crianças com problemas de aprendizagem. Dissertação de mestrado. Universidade Portucalense, Porto, Portugal. I35 f. Consultado em 2I de Novembro de 20I5, http://repositorio.uportu.pt/jspui/handle/II328/I5O

- Monteiro, A. P. T. de A. V. (2004). Biblioterapia como forma de Intervenção de Enfermagem de saúde mental e Psiquiátrica. Revista Hospitalidade, 264, I3-I7. Consultado em I4 de Novembro de 20I5, http://repositorio.esenfc.pt/rc/

• Ouaknin, M.-A. (1994). Bibliothérapie: lire, c’est guérir. Paris: Éditions du Seuil.

- Patrício, T. M. R. (20I4). Recomendações de leitura e terapias literárias. Dissertação de mestrado, Universidade de Lisboa, Lisboa, Portugal. I34 f. Consultado em I4 de Novembro de 2OI5, http://repositorio.ul.pt/handle/IO45I/ I8I64

- Pontes, M. do C. G. N. (2008). Da infância para o mundo: as leituras que educam para os valores e formam o carácter. Repositório Científico do Instituto Politécnico do Porto-RECIPP, I-I5. Consultado em 2o de Novembro de 20I5, http://recipp.ipp.pt//handle/IO4OO.22/267

- Sebastião, M. M. C. P. (2OI2). Biblioterapia: a função terapéutica do livro em ambiente prisional. Dissertação de Mestrado, Universidade Lusófona de Humanidades e Tecnologias, Lisboa, Portugal. 98 f. Consultado em I4 de Novembro de 20I5, recil.grupolusofona.pt/ handle/IO437/3653

- Shrodes, C. (1949). Biblioterapy: a theoretical and clinical - experimental study. Berkeley: University of California, I949. 344 f. Tese de Doutorado. Consultado em I2 de Julho de 20I5, http://www.faccrei.edu.br/gc/anexos/diartigosı8.pdf

- Silva, A. M. C. (20I4). Biblioterapia aplicada em contexto de saúde mental: um estudo de caso. 215 f. Dissertação de mestrado, Universidade Lusófona de Humanidades e Tecnologias, Lisboa, Portugal. Consultado em I4 de Novembro de 20I5, recil.grupolusofona.pt/ handle/IO437/5059

- Silva, M. P. T. da (2OII). Biblioterapia na educação pré-escolar: a gestão do medo e da agressividade. Dissertação de Mestrado, Escola Superior de Educação de Paula Frassinetti, Porto, Portugal. 74 f. Consultado em I4 de Novembro de 2OI5, http://repositorio.esepf.pt/ handle/IOOOO/ 479

-Van-Zeller, M. M. B. G. L. C. (2OII). A Biblioterapia como pedagogia atuante da leitura: 
um projeto de intervenção em contexto educativo. Dissertação de mestrado, Universidade Portucalense, Porto, Portugal. I53 p. Consultado em I4 de Novembro de 20I5, http://repositorio.uportu.pt/jspui/handle/ıI328/. 